ISSN 2073-445X

www.mdpi.com/journal/land/

Article

\title{
An Application for Regional Coastal Erosion Processes in Urban Areas: A Case Study of the Golden Horseshoe in Canada
}

\author{
Eric Vaz * and Lisa Bowman \\ Department of Geography, Ryerson University, Toronto, ON M5R 2B5, Canada; \\ E-Mail: lisa.bowman@ryerson.ca \\ * Author to whom correspondence should be addressed; E-Mail: evaz@ ryerson.ca; \\ Tel.: +1-416-979-5000.
}

Received: 5 September 2013; in revised form: 19 October 2013 / Accepted: 6 November 2013 /

Published: 13 November 2013

\begin{abstract}
Urban growth has had unprecedented consequences on environmental sustainability and anthropogenic activity. The eroding coastlines throughout the world are subject to the massive expansion of urban areas and the accountability of sustainable hinterland landscapes. The Golden Horseshoe is Canada's fastest growing region extending from the Niagara Peninsula and one of the most active economic regions in North America. This paper adopts a combined assessment of land use change and transitions in the coastal stretches of the Greater Golden Horseshoe. Comprising the urban expansion of the region between 1990 and 2011, an integrated assessment was carried out to: (i) detect changes in coastal lines along Lake Ontario; (ii) derive land use changes along the coast through spatial accounting matrices; and (iii) integrate climate change data for a combined assessment of future erosion loci. Visible erosion was found between the decade of 1990 and 2000, while certain areas have shown coastal recession in the southern region. The maximum recession was found to be $30 \mathrm{~m}$, with an increasing urban sprawl of $19.8 \%$ between 1990 and 2000. A combined temperature increase of $2{ }^{\circ} \mathrm{C}$ over the coming decades brings the increase in urban heat islands leading to the importance of combined land policies to mitigate the common problem of erosion in vulnerable urban stretches and liveability concerning spatial resilience of growing urban regions in North America.
\end{abstract}

Keywords: land use change; golden horseshoe; Toronto; GIS; coastal dynamics 


\section{Introduction}

\subsection{A Spatial Understanding of Coastal Areas}

The earth is a coastal planet totaling $1,634,701 \mathrm{~km}$ of coastline [1]. Due to the large distribution of coasts around the world the geomorphology of coasts is varied [2]. There are many different types of coasts including soft-shores, rocky shores and cliffs, hilly or flat coastal plains, narrow or wide coastal shelves and wetlands [3]. Climate types also vary, ranging from tropical and humid, to polar and dry, resulting in different biomes on land and in the aquatic systems [1]. Coastal zones are dynamic and not always the same size. In some regions they can extend a few hundred meters wide, while in others can contain physical and ecological features that are interconnected further [4] to include watersheds, drainage passages, floodplains, mangroves, swamps, estuaries, salt marshes, beaches, dunes, wetlands, barrier islands, coral reefs and tidal flats [5]. With 41\% of the world's population living within $100 \mathrm{~km}$ of the coast [2] it has been a popular location for living, leisure, recreational activities, tourism and primary ports for commerce [6]. Humans have taken advantage of the many opportunities the coasts provide, including clean water, food and waste disposal [7]. There is a wide breadth of knowledge of the ecological, economic and social importance of the oceans [8]. However, only recently has the importance of coasts been studied with the emerging technology of remote sensing and satellite imagery [2,9]. Coastal erosion has been of great concern, as it corresponds to the gradual wearing away of the beach or shoreline sediment due to wave action, often in regions where anthropogenic activity occurs. Coastal erosion is one of the most visible problems affecting coastal zones, with approximately $70 \%$ of beach receding around the world $[10,11]$. The natural formation of a coastline is due to changing sea levels and the impact of wave energy [12]. In 1990, [13] first stated in a report for the Intergovernmental Panel on Climate Change, that climate change will have significant impacts on the world's coastal zones particularly on sea level rise. It has also been stated that change of storm climate and human interference are also factors, but have been questioned because of the lack of evidence of long term increasing trend in storm severity [14], and uneven distribution of human degradation world-wide [11]. A general conclusion is that erosion is a natural phenomenon; however human action can speed up the process [15,16]. As discussed by [17], 40\% of Lake Ontario's coast is considered cohesive shorelines; these are cliffed (bluff) coastlines, where the profile contains non-resident materials with high silt and clay content. The main difference between cohesive shorelines and dynamic beaches is that cohesive shores erode anywhere from 0.3 to $2.0 \mathrm{~m}$ per year and do not have the potential to accrete, whereas dynamic beaches have the potential to accrete $[18,19]$.

\subsection{Anthropogenic Consequences of Coastal Regions in Canada}

This high rate of erosion leads to economic losses in properties, roads and agriculture lands, as well as additional costs in shoreline protection [20-22]. The eroding coastlines are causing irreversible damage to the waterfront and wetlands and are causing economic losses for the regions surrounding the Great Lakes [23]. Although there are many negative impacts to coastal erosion, some benefits are still mentioned throughout the literature. These include the generation of new sand and gravel, maintenance and extension of beaches, and preservation of some environmental habitats. Most of the negative impacts of coastal erosion in the Great Lakes are due to poor planning, incompatible 
development decisions and inadequate hazard zone buffers from the land-water interface. These topics are of a growing concern and have been reflected in many policy initiatives and management plans for Lake Ontario. Population along the coast is $10 \%-50 \%$ greater than interior regions and this increased use of coastal areas is threatening the delicate balances of these areas [24]. Increased population, expanding industrial space, increased beach tourism, fishing and climate change are among the top reasons for coastal erosion [25]. These factors can affect hydrologic patters, soil structure, natural vegetation, and morphological processes on the coastline [26,27]. With a high influx of people to coastal areas, there has also been an even stronger conversion from natural to artificialized land [28]. These human induced factors are speeding up the natural rate of erosion [15]. Management of coastal areas is an important and integral aspect for communities, providing social and economic value. Population increase, industrial plants, beach tourism and climate change are some major potential threats for coastal areas causing imbalance to the ecosystem. These can cause problems in coastal retreat such as sea level rising, decrease of sediment supplied to the coastal stretch and anthropogenic degradation of natural structures. Management of the coast is difficult because of the interaction of the dynamic-natural systems and socio-economic systems [29], and is of utmost importance in order to maintain sustainable development [30]. It has been stated that combining knowledge from different disciplines is best to understand and manage this complex phenomenon [12]. Our knowledge of these interactions is not yet perfected, and this relatively new topic has limited successful cases due to progress occurring incrementally [31,32]. Turner [12] states that in order to understand their interactions we must do more than monitor the processes. In this sense, modeling of environmental processes that effect coastal erosion is a necessary tool to be used in the management process. There is a general consensus among the literature that coastal erosion is occurring throughout the Great Lakes, and in Lake Ontario. It has also been noted the many negative effects this has on the surrounding areas. Urbanization has also been shown to speed this process up. Although there have been some studies conducted on the Great Lakes and erosion rates, there has been no research done on the relationship between erosion rates and urbanization, particularly along Lake Ontario. This study will aim to identify the relationship, predict future trends and be a starting point for other regional modeling, along with management of coastal areas. This paper offers a systemic analysis of the combined morphology of urbanization and land use transition processes, in line with changes along the coastal line of the Golden Horseshoe. These land use changes are suggest an increasing amount of urbanization, following loss of coastal stretches in detriment to agricultural land. We conclude that spatial analysis in a combination of land use change and coastal erosion processes, can lead to a better understanding of regional dynamics throughout the land, in particular in the area of the Golden Horseshoe in Canada where change is extremely expressive.

\section{Study Area}

The Golden Horseshoe (GH) (Figure 1) is the fastest growing region in North America [33]. Population in the GH is projected to increase to 11.5 million by 2031 [34] and contributed by the Ontario government, through the Ministry of Infrastructure. While recent years and following the economic recession in North America and changes in the immigration patterns, a slower pace may be applied [35]. This influx in population is placing an enormous strain on the natural capital that the region has to offer. Forests, wetlands and Canada's best agriculture land are being destroyed to urban 
sprawl. The provincial government Places to Grow Act, helping to establish policies for urban growth in Southern Ontario. In 2006 the Growth Plan for the GH stated that 40 percent of increased population had to be absorbed into preexisting built up areas [24]. This still leaves expansion for 2.7 million people, allowing this growth to develop the area into a megacity. Megacities can cause negative impacts on the coast, land and ecosystems, therefore careful management and sustainable development are paramount for planning expansion [33].

Figure 1. Typologies of anthropogenic land use in the Golden Horseshoe.

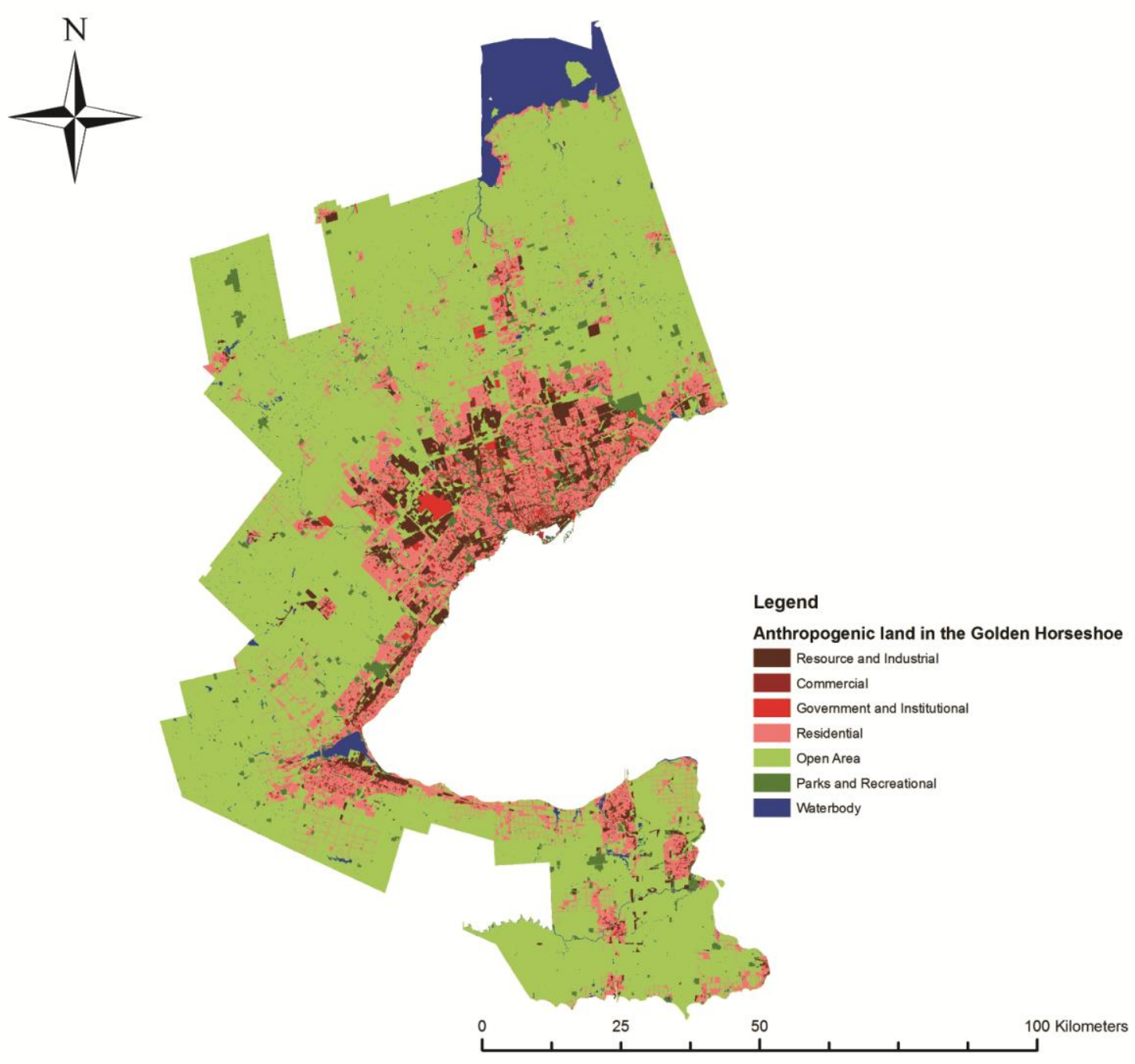

\section{Data Sources and Tools}

The United States Geological Survey (USGS) is a science organization that helps inform the public on environmental factors such as the health of the environment, natural resources and hazards, and climate change [36]. The USGS provides access to satellite imagery from many different sources such as Landsat, IKONOS, LIDAR and MODIS. For this project, Landsat 4 TM images were collected from the USGS Earth Explorer Program. July 1990, August 2000 and July 2011 were collected from path 17 row 30, that contained less than $10 \%$ cloud cover. They contained bands 1-7 and covered the full region of the study site. For land use classification, a mosaic of classified land (using Landsat imagery) was collected from a previous study [33]. These images were of the Golden Horseshoe (GH) 
and represent the study site along the coast. Furthermore, spatial climate data was added from SimCLIM. SimCLIM is a tool used for modelling climate change impacts and evaluating uncertainties for different climate factors. It produces projection of future climate and changes compared to the baseline climate. SimCLIM for ArcGIS, purchased from CLIMsystems, is an extension used in ArcMap 10.1 for global and regional climate models. This data contained regional climate models of Ontario with maximum, minimum and mean temperatures as well as average precipitation. The data could be run with a choice of six different emission scenarios and one of twenty scenario patterns. The predictions could be made up until the year 2100. Months could be selected individually or as a combined collection.

\section{Methodology}

Figure 2 (below) illustrates the project methodology devised. The methodology adopted divided the research into three parts: Part one details the work done in with the Integrated Land and Water Information System (ILWIS) deriving the coast line; part two details work done in ArcMap to show the change in land cover that has occurred; and part three details SimCLIM climate change models.

Figure 2. Combined methodology.

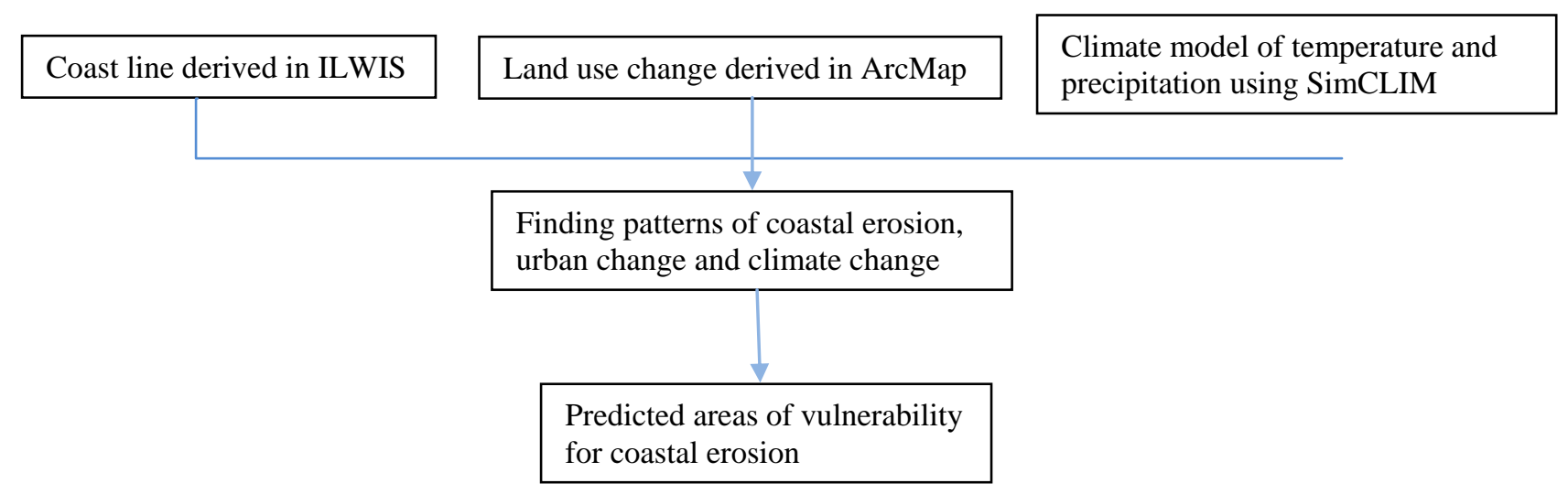

There have been several different methods used to detect coastal change using satellite imagery. Alesheikh et al. [37] successfully derived coastal erosion of Urmia Lake and his modeling process can be seen below in Figure 3. His process involves using the infrared band to separate water from the coast. According to [37], the first step of the process is to perform a radiometric calibration on the images. In Geomatica, the ATCOR2 function was used to perform an atmospheric correction of both the upper and lower levels of the atmosphere. This application runs both a radiometric correction, correcting for the reflectance values, and atmospheric correction, correcting for any haze/cloud cover [38]. In order to properly perform this function on the images, the date, time, latitude and longitude were require to be retrieved from the metadata and inputted to ascertain the correct/accurate solar zenith and solar azimuth. Additionally, the visibility (the distance at which objects of suitable size can be seen) was required to calibrate the sensor information; this was found on Environment Canada's National Climate Data and Information Archive website. The last step of the preprocessing was to georeference the images to a control image to ensure accurate correlation to facilitate the overlaying of images atop one another [37]. 
Figure 3. Extrapolated land use classification for 1990.

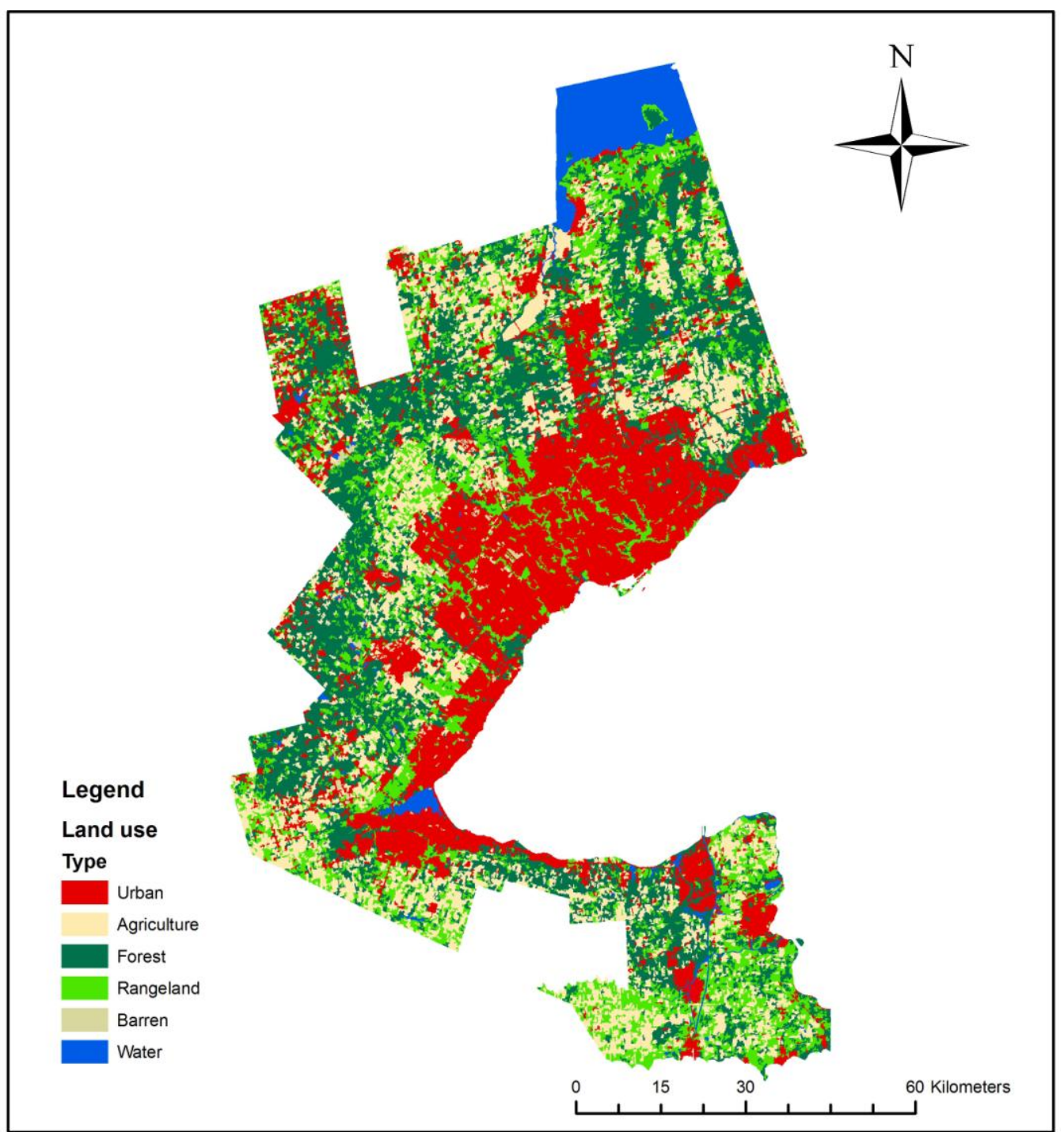

Once the preprocessing was completed in Geomatica, the images were brought over to ILWIS for coastal extraction. This model uses the histogram thresholding on the infrared band (band 5) to separate the water's low reflectance from the land's reflectance. Histogram thresholding is a tactic used to divide an image into constituent regions or objects; in this case it was used to determine the lake area. For band 5, the maximum and minimum values were determined for the water areas by observing the histogram. These values were then inputted into the Stretch function in ILWIS and created an output image for each band. However, ascertaining an accurate threshold value is difficult due to areas of mixed pixels resulting from pockets of land containing water in the transition zone [39]. To reduce this effect, a second condition is applied: the ratio of the satellite band 2 to satellite band 4 is set to greater than 1 and satellite band 2 to satellite band 5 is set to greater than 1 [37]. The output is a binary image of water and non-water areas of the coast of the lakes. This image and the band 5 thresholding image were then multiplied together. The resulting composite output image is then converted into a vector file and exported as a shapefile to be used in ArcMap. These steps were applied to the 1990, 2000 and 2011 Landsat images. 
An unsupervised classification was conducted on the images to decide what main reflectance categories were present. Six classes were chosen as the main categories of land-use that best represented the environmental characteristics of the topology of the land: Urban; Agriculture; Barren; Forest; Rangeland; and Water [33]. The unsupervised classification algorithm was constructed for all timestamps, namely for 1990, 2000 and 2010, and for each individual time stamp, the following steps were taken carefully into account: (i) identification of training sites resulting from similar values in the electromagnetic spectrum and their reflectance attributes; (ii) classification at a pixel level of each land cover class, and finally, the production of a thematic map, consistently identifying land use and land cover for the regional of the Golden Horseshoe in Canada. A post-classification change detection analysis was conducted on three images that have been collected and accurately classified (80\%) in the GH area over a span of 30 years (1990-2011) (Figure 3)

The classified data was received in vector polygons so the first step was to convert the polygons to raster files. This was done for the 1990, 2000 and 2011 data in ArcMap using the Conversion Tool Polygon to Raster function, with a cell size setting of 30 to produce a fine image resolution. To perform a post-classification image analysis, the raster images are required to be subtracted from each other. To demonstrate gradual topographical change, two different calculations were performed using the Raster Calculator tool; firstly change from 1990 to 2000, and secondly, change from 2000 to 2011. The table below (Table 1) shows the percentage change of land use types in the Golden Horseshoe between 2000 and 2010.

Table 1. Land Use allocation between 2000 (columns) 2010 (rows).

\begin{tabular}{cccccccc}
\hline & Urban & Barren & Agriculture & Rangeland & Forest & Water & Total \\
\hline Urban & $\mathbf{1 7 . 4 0 \%}$ & $0.26 \%$ & $3.84 \%$ & $2.66 \%$ & $2.50 \%$ & $0.09 \%$ & $26.74 \%$ \\
Barren & $0.22 \%$ & $\mathbf{0 . 1 8 \%}$ & $0.28 \%$ & $0.10 \%$ & $0.02 \%$ & $0.02 \%$ & $0.82 \%$ \\
Agriculture & $0.56 \%$ & $0.10 \%$ & $\mathbf{1 2 . 5 5 \%}$ & $5.33 \%$ & $1.62 \%$ & $0.03 \%$ & $20.19 \%$ \\
Rangeland & $0.89 \%$ & $0.06 \%$ & $5.36 \%$ & $\mathbf{9 . 2 3 \%}$ & $3.67 \%$ & $0.07 \%$ & $19.28 \%$ \\
Forest & $1.18 \%$ & $0.02 \%$ & $3.94 \%$ & $7.40 \%$ & $\mathbf{1 5 . 6 8 \%}$ & $0.16 \%$ & $28.37 \%$ \\
Water & $0.04 \%$ & $0.04 \%$ & $0.02 \%$ & $0.03 \%$ & $0.06 \%$ & $\mathbf{4 . 2 6 \%}$ & $4.44 \%$ \\
Total & $20.29 \%$ & $0.66 \%$ & $25.99 \%$ & $24.75 \%$ & $23.55 \%$ & $4.63 \%$ & \\
\hline
\end{tabular}

A closer assessment on the changes pertaining 2000 and 2010 (Figure 4), leads to a clearer understanding on the land use allocation in detriment of coastal urbanization in the Golden Horseshoe.

Urban sprawl has increased $6.45 \%$ while agricultural areas have decreased in detriment of urbanization $-5.80 \%$ followed by a similar decrease in rangeland $(-5.47 \%)$. This is particular concerning, as most agricultural and rangeland land use has become urban land in particular along Lake Ontario.

SimCLIM climate change model data was collected for regional climate modelling purposes. SimClim is an extension for ArcMap from CLIMSystems software that produces global and regional climate models. Ontario data was purchased online from their website. When generating a scenario, the CCCMA-31 (Canadian) pattern was used. Emission Scenario B2 was used with a sensitivity setting of "high". The B2 Emission Scenario was selected because it describes a world in which the emphasis is on local solutions to economic, social and environmental sustainability [40]. This family best described the current and predicted outcome for the GH (Figure 5). 
Figure 4. Land use dynamics and change between 2000 and 2010.

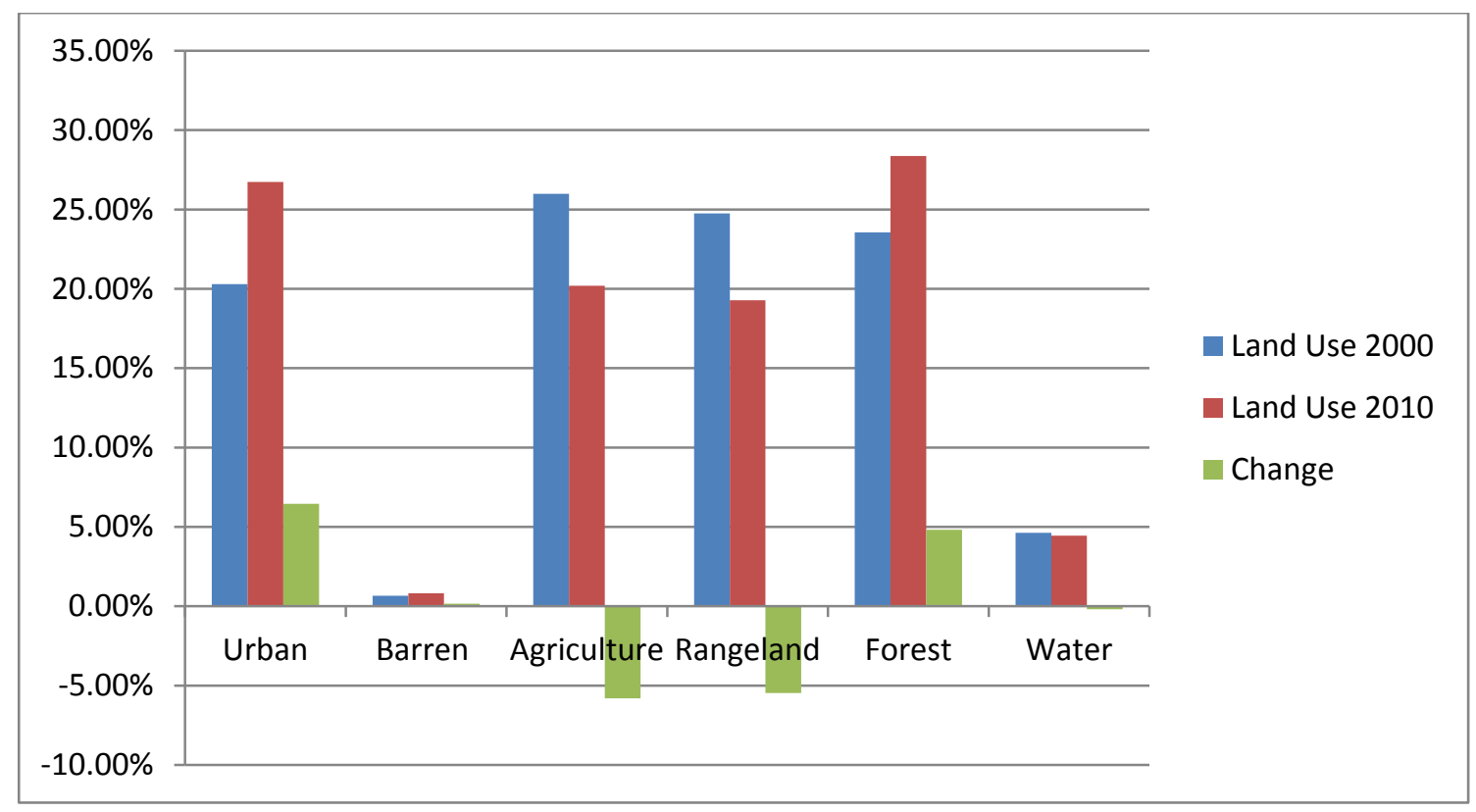

Figure 5. Maximum Temperature 2050.

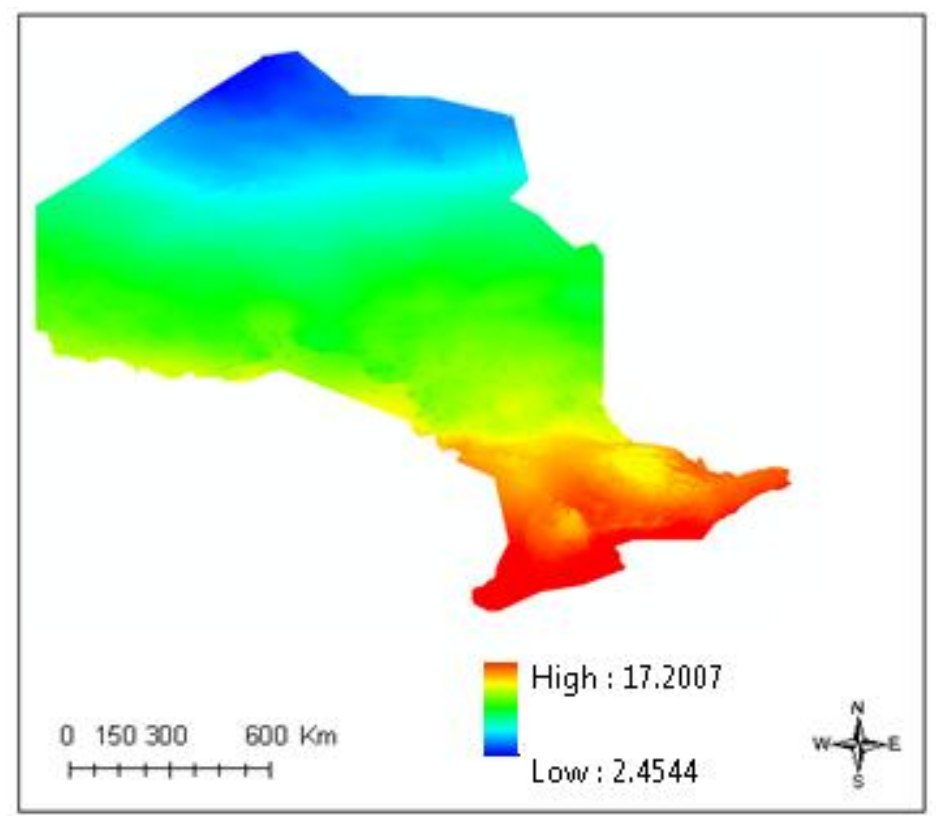

For each decade studied (1990, 2000 and 2011), data was collected for the existing coastline and land cover. Regional climate models of precipitation and temperature were also collected.

\section{Results}

Many areas have remained the same but there are some areas where the coast has grown and receded. There is more observable retreat of coastline occurring from 1990 to 2000, than there is from 2000 to 2011. The fluctuation of water levels, in particular the below average lake levels of 2011 [41], has a large effect on coastal growth and retreat. There are areas of coastal growth, from 2000 to 2011 that is notable along areas of urban development with an average growth of $15 \mathrm{~m}$. There is a noticeable 
trend of coastal retreat where rangeland is situated from 1990 to 2011 with an average retreat of $15 \mathrm{~m}$. Areas of barren land have the largest amount of unchanged coastline along Lake Ontario. At a regional level there are patterns of coastline recession, most notably in the Southern region. The maximum recession from 1990 to 2011 is 30 meters across, this is occurring East of Toronto and along the coast of Hamilton. There have been many changes to the landscape of the Golden Horseshoe, including an increase of urban sprawl from 1990 to 2011. The research findings indicate that from 1990 to 2000, $19.8 \%$ of all change that occurred was to urban land. From 2000 to $20117.2 \%$ of changes were to urban land. From 1990 to 2011, The Greater Toronto Area's urban classification has steadily grown and is currently almost entirely classified as urban land. With population growth estimated to rise in the region of 4.5 million people in the next thirty years, the amount of urban land is expected to increase proportionately. The most notable change between 1990 and 2011, is the amount of forest and rangeland that has become urban land; it is predicted that this trend will continue. This increase in urban land is causing a heat island effect, impacting regional temperatures and human health [42], further enhanced by the conclusions seen in steady increase in average temperature between 1990 and 2011. The predictions concerning climate change indicate that a continuous rise will be seen throughout the province, particularly in the Southern region where it is predicted that the average high temperature will be 17 degrees Celsius for the year. Mean temperature for Ontario is estimated to increase by over two degrees Celsius from 1990 to 2050. According to the Great Lakes Environmental Research Laboratory, this increase in temperature is the reason for declining lake levels [41], due to greater levels of evaporation, which is drying the lakes out. Although precipitation is shown to increase from 1990 to 2050, the most intense rainfall is surrounding Lake Erie, Lake Huron and Lake Superior and along the southern region of Lake Ontario. The quantitative interpretation carried out has led to several important conclusions concerning the integrated changes of in land use and erosion processes in the Golden Horseshoe: (i) there is coastal recession along the coast; (ii) the densest patterns of recession are found in areas of agriculture; and (iii) these changes have a spatiotemporal pattern. The research findings highlight the land most vulnerable to coastal erosion is rangeland and agricultural land surrounding urban centers. As climate change occurs, the increased risk of storms, flooding and wave action cause an increase of coastal erosion along these shores. The figure below (Figure 6), illustrates the calculated costal line surrounding Lake Ontario.

Within the subsection of the Golden Horseshoe, the largest section of coastal retreat is $30 \mathrm{~m}$ across. It should be noted that this region also has the highest precipitation and temperature levels in the province-both of which are contributing factors to lake levels and coastal erosion. There are noticeable trends of coastal erosion in locations of undeveloped land that is surrounded by urban development. Significantly, the data highlights erosion is occurring in areas of increased temperature and rainfall. The dynamic nature of Lake Ontario allows for periods of increased and decreased water levels thus exacerbating erosion [43]. The lower water levels in 2011 have been seen in areas of urban development and routinely affect property and infrastructure that was not designed to handle such fluctuations in water levels [44]. The lower lake levels are exposing the coast and making them more vulnerable to erosion [45]. Analysis of environmental predictions for 2050 suggests the highest increase in temperature and precipitation for Ontario will be in the areas adjacent to the western shoreline of Lake Ontario. This estimated increase in temperature and precipitation is predicted to lead to an increase in erosion along the coast. If current trends in urban expansion and climate change 
continue, as evidence in this research suggests, Lake Ontario can be expected to experience increased levels of coastal erosion over the next forty years. The estimated socio-ecological impact of this scenario would suggest discussion and analysis of potential environmental outcomes should be undertaken at a governmental level to ensure the protection and preservation of the natural environment around Lake Ontario for future generations. However, there is no federal ownership of the lake itself, which has contributed to the lack of government incentive and intervention on this issue [46].

Figure 6. Coast line in 2000.

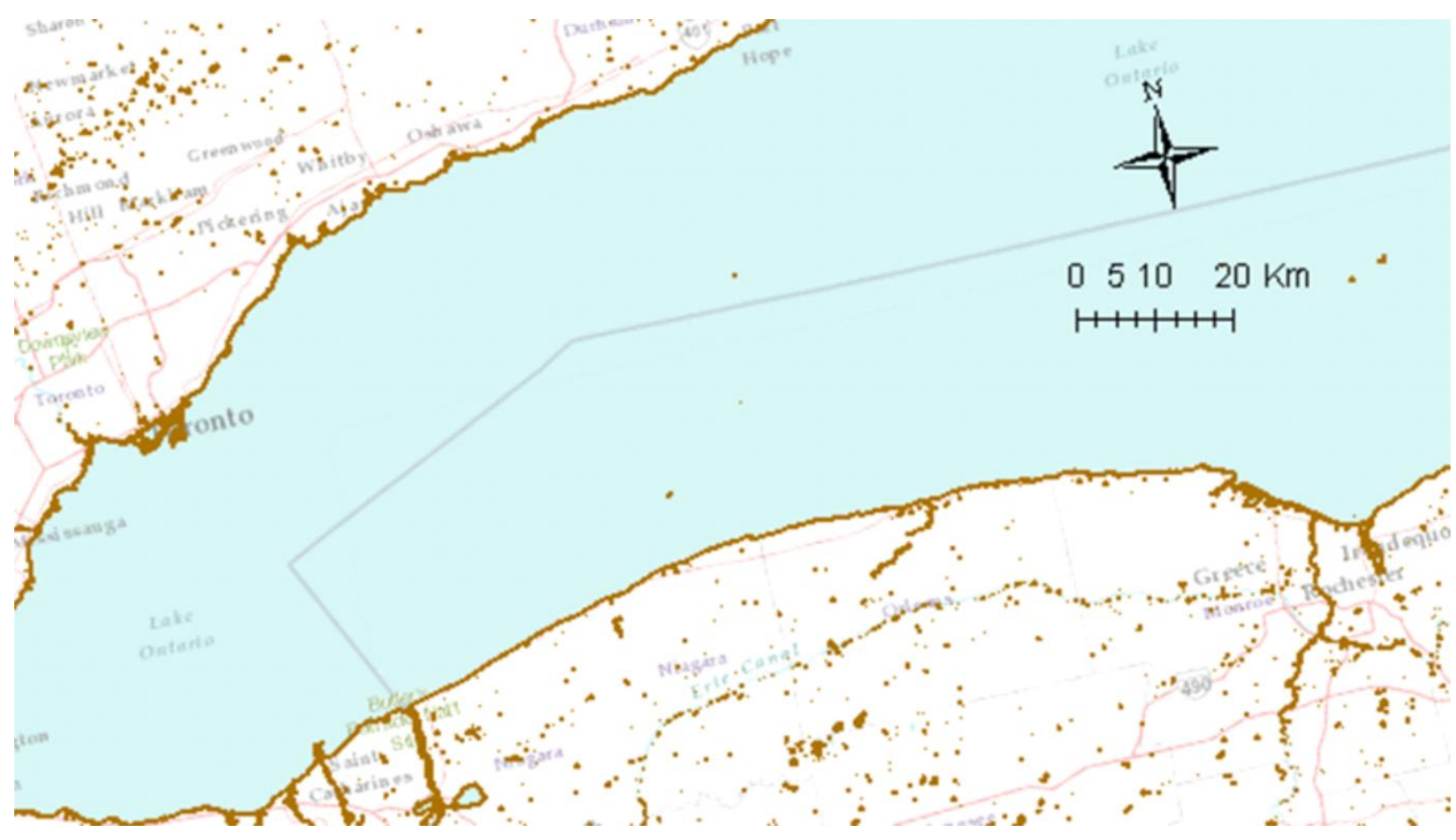

When assessing the process of coastal erosion, Geographical Information Systems (GIS) provides accurate and cost efficient results. Whilst principally a tool that can be used to derive coastal erosion, GIS also integrates other features; including change detection and regional climate models. This tool can be used for decision making and policy planning for ecosystems along the coast. GIS and spatial analysis can help support decision making relating to many spatiotemporal environmental processes through data analysis and visual aid [47]. Due to its powerful analysis capability and integrated approach, GIS can detect coastal changes and land use change, provide regional climate models on large and small scales and help visualize geographical information. The methods presented in this research can be seen as a useful guide for planning and conservation in the $\mathrm{GH}$ area, which is expected to see an increase in demographic population in the coming years. The methodology employed in this research can also be applied to other regional areas facing coastal erosion and urban expansion. This method is designed to help conservationists further understand the relationship between the human and natural environments and to inform their decision-making processes relating to ecological and conservational matters. Tourism relating to Lake Ontario's coastline forms a significant portion of the 
GH economy therefore preservation of the coastline is an integral aspect in the continued economic wellbeing of the region.

\section{Conclusions}

The spatial aspects of economic, demographic and land use processes are intrinsic for understanding the complexity of future outcomes of rapidly expanding urban regions. Geographic Information Systems and spatial analysis techniques provide important tools for accurate decision making, tackling the complexity of urbanization and accurate visualization of regional coastal changes when allied to monitoring land use allocation over time. The availability of several decades of satellite imagery and the advances in computational methods, have allowed to assess the Golden Horseshoe, a region of increasing demographic and urban change and debating with its future directions for sustainable development. This is the case in many regions throughout the world, where rapid sea level variability and impacts on vulnerable urban stretches are shaking the traditional limits of urbanization, and demanding new solutions on urban and coastal interactions. These negative impacts on anthropogenic land use call forth for modeling and coastal impact studies. It is the multi-temporal combination accrued with spatial dynamics of land use that, from a climate research perspective, must be dealt with to create more sustainable future landscapes and a livable environment. This paper has brought a combined technique of understanding: (i) land use transitions over the last decades in rapidly expanding areas; (ii) correlated these changes with the vulnerability of coastal stretches where urbanization seems to be significantly higher; and (iii) assess the dependency of climate change leading to warmer and less habitable areas in future. GIS and spatial analysis is only recently becoming more integrated into social sciences to help better understand the complex processes of our world. The methodology employed highlights the benefit in utilizing analysis tools such as deriving coastlines, change detection and regional climate models to produce visualizations, which can assist in understanding environmental impact and coastal erosion of the lakeshore areas. In turn, this greater understanding facilitates a more informed decision-making process. This research demonstrates the importance of a holistic, integrated approach to coastal modeling and the particular benefit in relation to understanding the interaction of human dynamics in such a fragile natural environment. As previous research has indicated, it is of upmost importance to preserve our coasts for ecological and economic reasons [20-22]. With the greater proliferation of techniques utilizing a combination of GIS and remote sensing, we are beginning to see a greater number of successful ecological management strategies being implemented and integrated into regional planning policies. This highlights the significant importance of providing more accurate solutions in coastal environment analysis predictions and the beneficial impact these studies can make $[47,48]$. This method is designed to help conservationists further understand the relationship between the human and natural environments and to inform their decision-making processes relating to ecological and conservational matters.

\section{Acknowledgments}

We would like to thank three anonymous reviewers for their very useful comments, and also the Journal Editorial Office for their always present support. And finally, this marvelous city: Toronto. Thank you. 


\section{Conflict of Interest}

The authors declare no conflict of interest.

\section{References}

1. Burke, L.; Kura, Y.; Kassem, K.; Revenga, C.; Spalding, M.; McAllister, D.; Caddy, J. Coastal Ecosystems; World Resources Institute: Washington, DC, USA, 2001.

2. Martinez, M.L.; Intralawan, A.; Vázquez, G.; Pérez-Maqueo, O.; Sutton, P.; Landgrave, R. The coasts of our world: Ecological, economic and social importance. Ecol. Econ. 2007, 63, 254-272.

3. Schwartz, M. Encyclopedia of Coastal Science; Springer: Dordrecht, The Netherlands, 2006.

4. Beatley, T.; Brower, D.J.; Schwab, A.K. An Introduction to Coastal Zone Management, 2nd ed.; Island Press: Washington, DC, USA, 2002.

5. Hinrichsen, D. Coastal Waters of the World: Trends, Threats, and Strategies; Island Press: Washington, DC, USA, 1998.

6. Miller, M.L.; Hadley, N.P. Tourism and Coastal Development. In Encyclopedia of Coastal Science; Springer-Verlag: Dordrecht, The Netherlands, 2005; pp. 1002-1008.

7. Duxbury, J., Dickinson, S.W. Principles for sustainable governance of the coastal zone: in the context of coastal disasters. Ecol. Econ. 2007, 63, 319-330.

8. Costanza, R. The ecological, economic, and social importance of the oceans. Ecol. Econ. 1999, 31, 199-213.

9. Berlanga-Robles, C.A.; Ruiz-Luna, A. Land use mapping and change detection in the coastal zone of northwest Mexico using remote sensing techniques. J. Coast. Res. 2002, 18, 514-522.

10. Pinto, P.; Cabral, P.; Caetano, M.; Alves, M.F. Urban growth on coastal erosion vulnerable stretches. J. Coast. Res. 2009, 56, 1567-1571.

11. Zhang, K.; Douglas, B.C.; Leatherman, S.P. Global warming and coastal erosion. Clim. Chang. 2004, 64, 41-58.

12. Turner, K. Integrating natural and socio-economic science in coastal management. J. Mar. Syst. 2000, 25, 447-460.

13. Tegart, W.J.; Sheldon, G.W.; Griffiths, D.C. Climate Change: The IPCC Impacts Assessment; Australian Government Pub. Service: Canberra, Australia, 1990.

14. Zhang, K.; Douglas, B.C.; Leatherman, S.P. East coast storm surges provide unique climate record. EOS Trans. AGU 1997, 78, 389-397.

15. Turner, K.; Lorenzoni, I.; Beaumont, N.; Bateman, I.; Langford, I.; McDonald, A. Coastal Management for sustainable development: Analysis environmental and socio-economic change to the UK coast. Geogr. J. 1998, 164, 269-281.

16. Li, R.; Liu, J.; Felus, Y. Spatial modeling and analysis for shoreline change detection and coastal erosion monitoring. Mar. Geod. 2001, 24, 1-12.

17. Amin, S.M.N.; Davidson-Arnott, R.G.D. A statistical analysis of the controls on shoreline erosion rates, Lake Ontario. J. Coast. Res. 1997, 13, 1093-1101.

18. Bishop, C.; Skafel, M.; Nairn, R. Cohesive profile erosion by waves. Coast. Eng. Proc. 1992, 1, 2976-2989. 
19. Davidson-Arnott, R. Introduction to Coastal Processes and Geomorphology; Cambridge University Press: Cambridge, MA, USA, 2010; p. 442.

20. Bryan, R.B.; Price, A.G. Recession of the Scarborough Bluffs, Ontario, Canada. Z. Geomorphol. Suppl. 1980, 34, 48-62.

21. Carter, J.P.; Guy, D.E. Coastal erosion: Processes, timing and magnitudes at the bluff toe. Mar. Geolog. 1988, 84, 1-17.

22. Davidson-Arnott, R.G.; Ollerhead, J. Nearshore erosion on a cohesive shoreline. Mar. Geol. 1995, $1224,349-365$.

23. Geomorphic Solutions. Introduction to Erosional Cohesive Bluff Assessment. In International Joint Commission as Part of the International Upper Great Lake Study; Geomorphic Solutions: Mississauga, ON, Canada, 2010.

24. Ministry of Infrastructure Ontario. Growth Plan for the Greater Golden Horseshoe. Available online: https://www.placestogrow.ca/content/ggh/plan-cons-english-all-web.pdf (accessed on 2 September 2013).

25. Vaz, E.; Walczynska, A.; Nijkamp, P. Regional challenges in tourist wetland systems: an integrated approach to the Ria Formosa in the Algarve, Portugal. Reg. Environ. Chang. 2013, 13, 33-42.

26. Ji, C.Y.; Liu, Q.; Sun, D.; Wang, S.; Lin, P.; Li, X. Monitoring urban expansion with remote sensing in China. Int. J. Remote Sens. 2001, 22, 1441-1455.

27. Ruiz-Luna, A.; Berlanga-Robles, C.A. Land use, land cover changes and coastal lagoon surface reduction associated with urban growth in northwest Mexico. Landsc. Ecol. 2003, 18, 159-171.

28. Craig, N.J.; Turner, R.E.; Day, J.W. Land loss in Coastal Louisiana (USA). Environ. Manag. 1979, 3, 133-144.

29. Pope, J. Responding to coastal erosion and flooding damages. J. Coast. Res. 1997, 13, 704-710.

30. Tzoulas, K.; Korpela, K.; Venn, S.; Yli-Pelkonen, V.; Kaźmierczaka, A.; Niemela, J.; James, P. Promoting ecosystem and human health in urban areas using Green Infrastructure: A literature review. Landsc. Urban Plan. 2007, 81, 167-178.

31. Olsen, S.; Tobey, J.; Kerr, M. A common framework for learning from ICM experience. Ocean Coast. Manag. 1997, 37, 155-174.

32. Shipman, B.; Stojanovic, T. Facts, fictions, and failures of integrated coastal zone management in Europe. Coast. Manag. 2007, 35, 375-398.

33. Vaz, E.; Buckland, A.; Worthington, K. A regional spatial-retrofitting approach to geovisualise regional urban growth: An application to the Golden Horseshoe in Canada. J. Spat. Organ. Dyn. 2013, 19, 1-12.

34. Hemson Consulting. The Growth Outlook for the Greater Golden Horseshoe; Greater Golden Horseshoe Forecast Committee. Available online: http://www.ontla.on.ca/library/repository/mon/ 9000/249757.pdf (accessed on 2 September 2013).

35. Bourne, L.S.; Britton, J.N.H.; Leslie, D. The Greater Toronto Region: The challenge of economic Restructuring, Social Diversity, and Globalization. In Canadian Urban Regions: Trajectories of Growth and Change; Bourne, L.S., Hutton, T., Shearmur, R.G., Simmons, J., Eds.; Oxford University Press: Don Mills, ON, USA, 2011; pp. 236-268.

36. US Geological Survey (USGS). Available online: http://www.usgs.gov/ (accessed on 10 August 2013). 
37. Alesheikh, A.A.; Ghorbanali, A.; Nouri, N. Coastline change detection using remote sensing. Int. J. Environ. Sci. Technol. 2007, 4, 61-66.

38. Richter, R. Atmospheric correction of satellite data with haze removal including a haze/clear transition region. Comput. Geosci. 1996, 22, 675-681.

39. Kamthonkiat, D.; Saiwanrunrkul, A.; Koshimura, S.; Matsuoka, M. Shoreline Anomaly Mapping Using Multi-Temporal Remote Sensing: The Recent Updates after the December 2004 Tsunami, in Phang Nga, Thailand. In Proceedings of 8th International Workshop on Remote Sensing for Disaster Management, Tokyo, Japan, 30 September-1 October 2010.

40. Arnell, N.W. Climate change and global water resources: SRES emissions and socio-economic scenarios. Glob. Environ. Chang. 2004, 14, 31-52.

41. National Oceanic and Atmospheric Administration. Great Lakes Water Levels. Available online: http://www.glerl.noaa.gov/data/now/wlevels/levels.html (accessed on 5 June 2013).

42. Rinner, C.; Hussain, M. Toronto's urban heat island-Exploring the relationship between land use and surface temperature. Remote Sens. 2011, 3, 1251-1265.

43. Eastern Research Group Inc. Marine Spatial Planning Stakeholder Analysis; NOAA Coastal Services Center: Charleston, SC, USA, 2010.

44. Keillor, P. Living on the Coast: Protecting Investments in Shore Property on the Great Lakes; Wisconsin Sea Grant and the US Army Corps of Engineers: Detroit, MI, USA, 2011.

45. Breffle, W.S.; Muralidharan, D.; Donovan, R.P.; Liu, F.; Mukherjee, A.; Jin, Y. Socioeconomic evaluation of the impact of natural resource stressors on human-use services in the Great Lakes environment: A Lake Michigan case study. Resour. Policy 2012, 38 152-161.

46. Paterson, S.K.; O'Donnell, A.; Loomis, D.K. The Social and Economic Effects of Shoreline Change: North Atlantic, South Atlantic, Gulf of Mexico, and Great Lakes Regional Overview; Eastern Research Group Inc.: Lexington, MA, USA, 2010.

47. Vaz, E.; Nijkamp, P.; Painho, M.; Caetano, M. A multi-scenario forecast of urban change: A study on urban growth in the Algarve. Lands. Urb. Plan. 2012, 104, 201-211.

48. Gurrutxaga, M.; Lozano, P.J.; del Barrio, G. GIS-based approach for incorporating the connectivity of ecological networks into regional planning. J. Nat. Conserv. 2010, 18, 318-326.

(C) 2013 by the authors; licensee MDPI, Basel, Switzerland. This article is an open access article distributed under the terms and conditions of the Creative Commons Attribution license (http://creativecommons.org/licenses/by/3.0/). 